\title{
KONRAD SZOCIK
}

\section{$\stackrel{\circ}{\text { II }}$ \\ THE IMPACT OF RELIGION ON THE EVOLUTION OF COOPERATION AND CONFLICTS}

\begin{abstract}
Konrad Szocik, The impact of religion on the evolution of cooperation and conflicts, edited by Z. Drozdowicz and S. Sztajer, "Człowiek i Społeczeństwo”vol. XLI, Poznań 2016, pp. 177-188, Adam Mickiewicz University Press. ISSN 0239-3271.

Religion and religious beliefs have continued to play an important role in the evolution of the ability to cooperate at the level of large groups. It seems that natural selection favours selfishness rather than cooperative tendencies. Therefore, we suggest that cultural selection was necessary for the evolution of pro-social forms of behaviour. Cooperation is connected with conflicts, which are used to develop in-group cooperation. Here I show the possible impact of religion and religious beliefs on the development of an ability to cooperate, and to generate conflicts which are strictly connected with the possibility of in-group cooperation.
\end{abstract}

Konrad Szocik, University of Information Technology and Management in Rzeszow, ul. Sucharskiego 2, 35-225 Rzeszów, Poland, e-mail: kszocik@wsiz.rzeszow.pl

\section{Introduction}

Religion has long served many important functions. One of them consists in the regulation of social relations in terms of collaboration, cooperation, but also of competition. Religion is typically presented as a cultural phenomenon conducive to developing cooperation and pro-social behaviour. Special emphasis is put on the role played in the development of intra-group trust, for instance, as a result of activating mechanisms typical of "parochial altruism" - exposing intra-group trust coming about in opposition to a competing and potentially threatening group. Religion and religious convictions can 
also motivate conflictual behaviour. Cooperation remains strictly bound to the potential to generate and maintain conflicts; as such conflict situations require prior consolidation of the group, and conflicts (especially those of the inter-group variety) increase the level of cooperation and mobilisation. Cooperation for the sake of rivalry and conflict is also a frequent phenomenon. The purpose of the present article consists of focusing attention on some basic characteristics of religious convictions and of religion, which are connected with the capacity to motivate for cooperation and conflict.

\section{Natural selection and the possibilities of cooperation}

Even if religion and religious convictions have indeed contributed to developing capacities for cooperation, then this potential impact of religion is worth considering in the broader context of the mechanisms of natural selection, as well as in the context of the possibility of developing cooperation in general, in relation to natural and cultural selection. It seems that natural selection, especially at the level of the individual, promotes egoism rather than cooperation and altruism. Therefore, the development of a perfect degree of cooperation and a maximisation of pro-social attitudes meets a basic obstacle in the form of an evolutionary promotion of selfish behaviour aimed primarily at guaranteeing the survival of the individual. ${ }^{1}$ Even nowadays, in spite of the necessary reference to the welfare and interest of others, as well as the awareness of the positive role played by cooperation, a constant egoistic component focused on one's own survival is required. Natural selection seems to favour evolutionarily low-cost mechanisms, such as deception, the abandonment of cooperation, or mimicry. If two individuals are to obtain the same profit, but one of them truly and honestly performs the duties necessary to get the desired payback, while the other may reach the same result through putting on an act, then deception and fakery provide an easier and lower-cost mechanism. Apart from egoism and the preference for low-cost strategies, another evolutionary barrier characteristic of natural selection and limiting the capacity for the natural development of cooperation comes in the form of the life-style characteristic of the Pleistocene epoch. For most of their history, humans have lived in small groups of next-of-kin individuals, who were highly dependent on each other. Thus, attitudes towards unknown strangers was characterised by distrust and distance rather than openness

${ }^{1}$ R. Boyd, P.J. Richerson, Culture and the evolution of human cooperation, Phil. Trans. R. Soc. B (2009) 364, pp. 3281-3284. 
and readiness for cooperation. If these deep evolutionary roots of emotions and states such as aggression, fear or anger are taken into account, natural selection seems a force precluding rather than promoting a development of the capacity to cooperate among unrelated strangers outside of the scope of small groups. It would not be warranted, however, to conceive of cooperation as a feature abnormal or contradictory from the point of view of natural selection, as in such a case it would be difficult to imagine the possibility of its evolutionary emergence as a phenomenon standing in contradiction to the biological orientation of the organism.

The basic mechanisms of natural selection comprise kin selection and reciprocal altruism. According to Hamilton's rule, kin selection assumes that the degree of kinship must surpass the ratio between the costs and profits of the altruist act. Reciprocal altruism is based on a tit-for-tat rule, and states that the probability of a subsequent meeting of the same individuals must be greater than the calculus of profits and costs associated with an altruist act. Both these mechanisms do not function at the level of large groups and allow only for cooperation within small groups. ${ }^{2}$ Ara Norenzayan points out that even for small-scale groups of approximately 300 individuals there is a necessity of cultural mechanisms being in place in order to facilitate the maintenance of social relations. ${ }^{3}$ Norenzayan refers to Rodney Stark's research, which demonstrated that $24 \%$ of 427 pre-industrial cultures possessed some concept of God engaged in human affairs and supporting morality. ${ }^{4}$ The lack of the concept of great moral gods in a majority of cultures of that period, suggests that at the small-group level the aforementioned biological mechanisms of kin selection and reciprocal altruism were sufficient for regulating social relations. A low head-count of the group did not require an introduction of extra-biological mechanisms enabling cooperation, as the kinship relations and reciprocal dependencies of group members effectively enforced compliance with the interests and aims of the group.

In Norenzayan's view, the problems characteristic of the ways in which social groups function were connected to the necessity to guarantee cooperation and coordination, which were especially vital for the sufficient provision of water, especially in the face of shortages. Therefore, cooperation constituted a capacity of strategic importance for the group. The ability to cooperate was meant to protect the group members against mutual aggression

${ }^{2}$ M.A. Nowak, Five Rules for the Evolution of Cooperation, "Science" vol. 314, 8 December 2006, pp. 1561-1562.

${ }^{3}$ A. Norenzayan, Big Gods: How Religion Transformed Cooperation and Conflict, Princeton University Press 2013, pp. 125-126.

${ }^{4}$ Ibidem, p. 127. 
and exploitation, as well as to enable the group to prevail in a situation of conflict against another group. It is worth emphasising that the way of guaranteeing a relevant degree of cooperation at a lower level of competition, i.e., the intra-group, constitutes a complex question. On the one hand, the previously mentioned life in a small group and the important role played by kinship relations and strict mutual dependencies among group members should theoretically mobilise members to honest cooperation. This presumption seems to be efficiently implemented in small groups due to the personal familiarity with all or almost all group-members, the lack of anonymity as well as the relative ease of identifying the perpetrator of a socially undesirable deed. On the other hand, it would seem that individuals refusing an honest cooperation would be preferred by natural selection in a situation of intra-group rivalry without the factor of inter-group competition. Only at a higher level of competition, i.e., the inter-group, should natural selection promote cooperating individuals - due to the risks of endangerment and failure involved in competing with a neighbouring group. ${ }^{5}$ This reference to rivalry points to two questions. Firstly, it suggests the insufficiency of natural selection mechanisms, which need not promote cooperation within one's own group in the case of there being no inter-group rivalry. Secondly, there seems to be a strong correlation between cooperation and conflict situations. In this paradigm, a conflict situation at the inter-group level appears indispensable for the evolution of cooperation.

Consequently, we might assume that natural selection does not support the capacity to cooperate at the level of large groups including strangers. The insufficiency of the mechanisms of natural selection suggests the necessity to refer to the phenomena of cultural selection, without which the capacity to cooperate could not be developed. The characteristics of natural selection, which promotes selfishness and has only functioned at the level of small and interrelated groups throughout much of human history, can explain the omnipresence of legal systems and of religious convictions in various cultures by reference to the pro-social function and the capacity to motivate cooperation. It seems that an equally important aim of the development of religious convictions was their psychological and therapeutic function, which must have presupposed some forms of social relations and was conducive to the emergence of the belief in the immortality of the soul. With respect to the social function of religion, it seems that it was mainly responsible for coordinating and ensuring the internal cohesion of a large group. The latter two functions can be exemplified by reference to great monotheist

${ }^{5}$ M.A. Nowak, Five Rules... 
religions based on the concept of a great moral God. Judaism demonstrates this role by the divine legitimation of intra-group norms symbolised by the ten commandments. Christianity introduces the term "brothers and sisters" with respect to such strangers whose community of religious convictions is sufficient for positing a fictitious kinship. In this sense, we could claim that religion was aware of the importance of kinship relations and of the role of the family, and accepted the necessity to relate to one of the greatest and most permanent biological forces in order to consolidate unrelated, strange persons.

\section{Cooperation and religion}

In light of the above remarks, I follow Herbert Gintis in assuming that the development of the phenomena and institutions within the frame of cultural selection was key for the emergence of cooperative behaviour. Without those institutions, the development of patterns beneficial to the group on the basis of natural selection seems only possible within small groups with a limited rate of migration. However, inter-group migrations have been intensive and frequent. Another condition important for natural selection is an intensive selective pressure. We may assume that the development of cooperative behaviour at the large-group level constitutes a result of the human capacity for creating social institutions ${ }^{6}$. Natural group selection, which is an alternative tool potentially capable of generating this capacity, requires the satisfaction of conditions rather impossible to occur in dynamically expanding Holocene communities, with their high rates of migration.

In what way could religion have become a tool useful for developing cooperation? One of the hypotheses invoked by Norenzayan assumes that the places of worship among hunter-gatherers may have congregated large groups of people, whose feeding required the invention of experimental methods of cultivating plants and herding animals. This hypothesis interprets religious convictions as a precursor to the development of agriculture, which would then stimulate its development. Therefore, religious convictions are not to be treated as a side-effect of the emergence of a sedentary lifestyle and of agriculture.

Another explanation of the role played by religion is provided by Bernard Crespi and Kyle Summers, whose account of the origins of religion is

${ }^{6}$ H. Gintis, S. Bowles, R. Boyd, E. Fehr, Explaining altruistic behavior in humans, “Evolution and Human Behavior” 24/2003, p. 166. 
provided within the framework of the "inclusive fitness theory.” This theory claims that individuals are driven by the maximisation of their own gains rather than those of the group. Applied to the study of religion, this theory takes religion to constitute a form of cultural adaptation which served the needs of group survival, for instance by decreasing the rate of intra-group conflicts, as well as it facilitated the rivalry over resources with other groups. Within this approach, religion (and especially the notion of God), is seen as a consequence of the biological tendency to maximise one's own gain in line with the presumption of an "inclusive fitness theory." The assumption is that the maximisation of individual gain is achieved through the maximisation of group gain. ${ }^{7}$ Natural selection might promote egoistic behaviour of the individual, but it may so happen that individually egoistic behaviour turns out to be in line with actions benefiting the group.

This explanation combines cultural and natural selection, and it does also perceive in religion an alignment with the evolutionary preference for features and strategies boosting the survival chances of the system. Dominic Johnson assumes that the faith in the supernatural observer and judge might be interpreted as an adaptation of natural selection. In spite of the costly nature of such a system, which may restrict the liberty and freedom to enact egoistic tendencies, the fact that one follows religious convictions, and especially such that involve a belief in a supernatural observer, may protect the individual against the socially negative consequences of egoistic acts which might be detected and punished by society. Certainly, according to Johnson, the development of language and the theory of mind increased the chances of unwelcome acts being detected by society. ${ }^{8}$ Carl Darwin also assumed that some values, such as patriotism, fidelity or courage, constitute elements preferred by natural selection, when they increase the chances of group survival. David Sloan Wilson has a similar view of religion, which may be seen as an evolutionary product allowing for groups to function as adaptive units. ${ }^{9}$ Apart from the gains at the group level, the possibility of individual gains is also pointed out.

An application of this theory to religion is also developed by Richard Alexander. Alexander suggests that the notion of God might have arisen as a metaphor of the circle of kinship. Religious tales might have been useful for increasing group gains. Their presumed indisputability might have

${ }^{7}$ B. Crespi, K. Summers, Inclusive fitness theory for the evolution of religion, "Animal Behaviour” 92/2014, pp. 314-315.

${ }^{8}$ A. Norenzayan, Big Gods..., p. 135.

${ }^{9}$ Ibidem, pp. 140-141. 
promoted cooperation through presenting pro-social forms of behaviour as unquestionably true facts. Secondly, those tales may have promoted good behaviour through introducing the fear of punishment on the part of the supernatural being. The concept of the supernatural being is used for the sake of coordinating group activities aimed at strengthening cooperative capacities. ${ }^{10}$ Acceptance of the notion of God is understood by Alexander as an illustration of the desire for reference to a unifying force, which is also a source of positive emotions.

Alexander perceived the concept of God as a cultural referent of biological functions. God is understood to be the giver of life. Serving God is an equivalent of serving the circle of kinsmen and acquaintances. God's justice symbolises honesty in intra-group relations. God's omnipotence expresses the law-giving and controlling force of the group. God's omniscience reminds us of being reciprocally observed in small social groups. Alexander considers these attributes of God refer to the functions and characteristics of cooperating groups.

In this context, it seems worth considering whether the development of the capacity to cooperate at the level of large groups could be possible without conflicts and inter-group rivalries. The phenomenon of cooperation for the sake of rivalry appears to be an instinct of special importance for young men. The recognition of a proclivity for aggression and risk as a feature characteristic of young men is explained by the hypothesis of the male-warrior. ${ }^{11}$ These characteristics are provided with foundations at the level of inter-group rivalry, when a closely cooperating group moves against another neighbouring group - a potential rival or even a threat. The role played by inter-group rivalry and external threats seems vital for maintaining a relevant degree of cooperation - as in line with the decline of the inter-group and external rivalry, egoistic tendencies are on the rise.

Scott Artan observes in this context that the rational motivation for the mechanisms of social behaviour is insufficient for the maintenance of loyalty and advantage in rivalries. Therefore, even secular groups implement quasi-secular forms. ${ }^{12}$ The religious approach assumes irrationality or perhaps non-rationality, and it is confronted with the rational approach entailing a pragmatic analysis of gain and loss. Norenzayan points out that it is through those characteristically religious mechanisms of irrational or extra-rational

${ }^{10}$ B. Crespi, K. Summers, Inclusive fitness theory..., p. 4.

11 Ibidem, pp. 7, 9.

12 S. Atran, God and the ivory Tower, http://foreignpolicy.com/2012/08/06/god-andthe-ivory-tower/ [access: 22.12.2015]. 
decision-making that religions were capable of gaining advantages in inter-group rivalry. Successful religious convictions were spread and accepted by other groups. Their social efficacy might explain the global popularity of religions and religious convictions. ${ }^{13}$

\section{Conflicts and religion}

It seems that the mechanisms serving the development of cooperation intermingle with those generating conflicts. This seems to stem from the fact that cooperation is boosted by conflict situations. One could even assume that conflicts are indeed indispensable for the development of this capacity. As I have already mentioned, religion is based on natural mechanisms related to cooperation and conflict. Three features characteristic of religion can be singled out, which constitute its theoretical conflictual potential. Religion refers to the idea of the supernatural judge. Lack of acceptance of this notion by other groups or the lack of understanding for this notion can breed suspicion, and subsequently ill-will and aggression with respect to those groups. In a conflictual situation, religious rituals might strengthen the intra-group cooperation and coordination of actions against rival groups. Rituals might sharpen the inter-group antagonisms. Finally, religion presumes the existence of holy values, which are non-negotiable.

The conflictual potential of religion is correlated with its pro-social inclinations. The tendency for altruistic actions is strongest among the religious with respect to their co-religionists. Christians are most helpful to other Christians. In this sense religion and religious convictions are based on tribal psychology and primitive instincts. They expose inter-group boundaries. Also the acts of suicidal terrorism can be interpreted through the prism of the mutual reference of intra-group altruism and trust with inter-group aggression, which is typical of "parochial altruism." Support of the religious group for such acts is proportional to the frequency rate of the religious practices, but not with the frequency of prayer.

Holy values, which need not be restricted to religion and may have an application to a secular cultural order, are based on the model of a "devoted actor" and not on that of a rational agent. Such a model of action does not include rational or empirical criteria, and does not allow for any negotiations of values or ideas. This model does theoretically guarantee a higher durability and efficiency than the rational model, as it excludes the possibility of

${ }^{13}$ A. Norenzayan, Big Gods..., p. 143. 
abandoning hitherto accepted values or strategies for the sake of values or actions considered more attractive; and this is what the non-negotiability of holy values amounts to.

As it was pointed out by Norenzayan, outside of the western civilizational circle, social trust is based on kinship, the perception of honour and ethnic solidarity. Frequently, all these elements are rooted in religion. In secularised states, however, "great gods" have been superseded by "great governments." ${ }^{14}$

\section{Advantages of religious groups}

Shared religious convictions within a group may lead to the religious group gaining an advantage in an inter-group rivalry. Religious convictions may have a beneficial impact on the individuals, as well as on the group as a whole. The positive influence of religion on the individual concerns mostly the beneficial impact on physical and psychological help. On the social level, religion may guarantee social support and produce bonds among unrelated individuals. Theoretically, it is capable of introducing a sense of meaning which cannot be realised within any secular belief-systems, as it assumes the existence of a parallel reality. This meaningfulness may prove useful when it comes to inter-group rivalries over resources, and provide motivations for coordinated efforts. An empirical validation of this practical utility of religion can be provided by the example given by Richard Sosis of two hundred communities which emerged in the United States in the $19^{\text {th }}$ century. After the first two decades since their foundation, $6 \%$ of the secular and $39 \%$ of the religious communities were still in existence. It is also Rodney Stark that emphasises this special potential of religion. He explains the success of Christianity in the Roman Empire by the specifically Christian trust, altruism, as well as the capacity for devotion, especially when it came to the care of the very sick.

Statistically, a majority of conflicts in the history of humanity did not have religious causes. The higher frequency of secular than religious causes may suggest a more peaceful than conflictual orientation of religion, which may have only been a political tool rather than an immanent source of conflict. ${ }^{15}$ The "War Encyclopaedia" demonstrates that of 1763 conflicts

${ }^{14}$ Ibidem, p. 171.

${ }^{15}$ K. Szocik, Czy uzasadnione jest wiqzanie wojny z religiq?, "Studia Polityczne" 3(39)/2015, pp. 167-181. 
only 123 (7\%) had a religious reference. However, the BBC cycle "God and war" was evaluating the religious motivation of conflicts throughout the last 3500 years. On a scale ranging from 0 to 5 , the Punic wars were judged not to have had any religious motivation (0), the crusades had a strong religious foundation (5), while roughly $7 \%$ of all conflicts were given an index of religious motivation higher than 3. It was also established that over $60 \%$ of all conflicts had no religious motivation. ${ }^{16}$ Therefore, while in statistical terms the religious motivation may have been of lesser significance than non-religious motives, still under certain conditions the reference to religious conviction is capable of generating conflict situations. This concerns the aforementioned role of rituals. In this context, a correlation might be spotted between the degree of inter-group antagonism and the level of intensity with which such rituals are practised which boost inter-group solidarity.

\section{Conclusions}

The development of the capacity to cooperate at the level of large groups required a simultaneous influence of both natural and cultural selection. The mechanisms of natural selection, which promote individual survival and selfishness, implied also the growth of cultural phenomena boosting the chances of group-survival. The development of religion might be interpreted in terms of increasing the chances of group survival thanks to the development of the capacity to cooperate. In this sense, religion is a cultural phenomenon, whose emergence may have been motivated by natural selection. In turn, the conflictual potential is strictly correlated with the capacity to cooperate, as the capacity and readiness to start and run a conflict requires previous cooperation and motivation for coordinated action. Conflict situations also stimulate pro-social behaviour. In this sense, the relationship between religion and cooperation implies the question of conflict. Religion is based on and boosts tribal psychology and tribal instincts exposing inter-group boundaries. It seems that in this psychological context the relation of religion to cooperation, conflict and competition constitutes a natural environment for the development and functioning of religious convictions.

Utility of religion stems from the specific content of religious convictions. The postulated existence of a second, parallel reality - whose priority over the terrestrial is asserted - implies the existence of duties on the part of the individual to this other world. The key role is played here by the

\footnotetext{
${ }^{16}$ S. Atran, God and the ivory Tower.
} 
concept of God/gods understood as beings with special skills, and especially beings endowed with omniscience and omnipotence, who evaluate human behaviour in terms of prizes and punishments. On the one hand, the religious persons assume that the "great" gods are omniscient. On the other hand, in line with the hypothesis of theological incorrectness, the believers might treat this omniscience selectively and accept the access of God/gods mostly to such information that proves socially strategic. ${ }^{17}$ Apart from the phenomenon of theological incorrectness, various religious systems have also featured mechanisms minimising the potential negative consequences of being observed by God/gods, such as for instance the concept of the absolution of sins. The existence of such mechanisms might be seen as the result of the primary concept of the natural selection, i.e., the promotion of low-cost strategies such as feigning or evading honest cooperation.

In turn, the evidence of association between cooperation and the conflictual potential of religion can be seen in the research results of Jean Decety, who proved that non-religious children tend to be more generous than the religious ones. Yet, the religious children are supposed to have a stronger proclivity for punishing transgressions. Dacety points to the phenomenon of "moral concession," which is present among the religious persons. It consists in the conviction on the part of the religious that they have the right to act in an immoral way due to the idea of their own perfection or of the immanent moral correctness stemming from religious belonging. ${ }^{18}$ It seems that religious convictions may affect human behaviour in a special way due to their content suggesting the existence of another reality. On the other hand, as pointed out by Norenzayan, the superseding of religion by secular systems of law and politics may suggest the necessity of some cultural mechanisms that ensure the emergence and maintenance of cooperation. In this case, the role of religion might turn out to be accidental rather than necessary in the evolution of cooperation - although Norenzayan suggests an exceptional potential of the religious content. Nevertheless, we may doubt such a simple impact of formally efficacious religious content on the practical and effective social consequences that they generate. According to the principle of natural selection, people always behave somewhat selfishly, and both in reference to religion and other cultural phenomena boosting the capacity to cooperate, such as the legal system or trade, their behaviour will be tainted by the risk of deception or the simulation of honest cooperation. In the case of religious

\footnotetext{
17 A. Norenzayan, Big Gods, p. 130.

${ }^{18} \mathrm{~J}$. Decety et al., The negative association between religiousness and children's altruism across the world, "Current Biology” 25/2015, November 16, pp. 1-5.
} 
convictions, the existence of the phenomenon of religious incorrectness may suggest that the theoretically pro-social potential of religion and of religious convictions had undergone an attempt at neutralisation and limitation by allowing for a selective and subjective evaluation of the conditions under which the omniscience and omnipotence of God/gods may transpire. 